\title{
Twelve Tips for Developing a Global Community of Scholars in Health Professions Education
}

Subha Ramani, Judy McKimm, Ardi Findyartini, Vishna Devi Nadarajah, Richard Hays,

Margaret S. Chisolm, Helena P. Filipe, Alice Fornari, Elizabeth K. Kachur, Rashmi A. Kusurkar, Harish Thampy, Keith W. Wilson

\section{Corresponding author:}

Dr. Subha Ramani

Associate Professor of Medicine, Harvard Medical School

Director, Program for Research, Innovations and Scholarship in Education, Department of

\author{
Medicine \\ Brigham and Women’s Hospital \\ 75, Francis Street \\ Boston, MA 02115, USA \\ Email: sramani@bwh.harvard.edu \\ Phone: +1-617-525-7504
}

Notes on contributors 
Subha Ramani, MBBS, MMEd, PhD, FAMEE, is Director, Program for Research, Innovations and Scholarship, Department of Medicine, Brigham and Women's Hospital; and Associate Professor of Medicine, Harvard Medical School, Boston, USA. ORCID: 0000-0002-8360-4031

Judy McKimm, MBA, MA, BA, PGDip, Cert ED, FAMEE, FAoME, SFHEA, is Professor of Medical Education and Director of Strategic Educational Development at Swansea University Medical School, Wales, UK. ORCID: 0000-0002-8949-5067

Ardi Findyartini, MD, PhD, is the Head, Department of Medical Education and Medical Education Unit; Head of Cluster, Centre for Medical Education, Indonesia Medical Education and Research Institute, Faculty of Medicine Universitas Indonesia. ORCID: 0000-0002-96013994

Vishna Devi Nadarajah, BSc (Hons), MHPE, PhD, is the Pro Vice Chancellor Education and Institutional Development at the International Medical University, Kuala Lumpur, Malaysia. ORCID: 0000-0002-7126-7189

Richard Hays, MD, PhD, FRACGP, FANZAHPE, FAoME, FAMEE, combines work in rural family Medicine one with academic roles in medical education in both undergraduate and postgraduate programs at James Cook University in Australia, with particular interests in curriculum design, assessment methodology and program evaluation. ORCID: 0000-0002-38753134

Margaret S. Chisolm, MD, FAMEE, is Vice Chair for Education and Professor of Psychiatry and Behavioural Sciences, and of Medicine, at the Johns Hopkins University School of Medicine. ORCID: 0000-0001-7424-919 
Helena Prior Filipe, MD, MMEd, AFAMEE, FSACME is a consultant of Ophthalmology practicing in Hospital das Forças Armadas/PL-EMGFA and Hospital SAMS in Lisbon, Portugal. She serves the International Council of Ophthalmology, ICO as chair of the CPD area of focus and is a member of the Directive Board of the College of Ophthalmology. ORCID: 0000-0002-1081-7570

Alice Fornari, EdD, RDN, is Associate Dean, Donald and Barbara Zucker SOM at Hofstra/Northwell and Vice President, Faculty Development at Northwell Health System, USA. ORCID: 0000-0001-5475-2732

Elizabeth Krajic Kachur, PhD, FAMEE, is Director of Medical Education Development, Global Consulting, New York, USA.

Rashmi A Kusurkar, MBBS, MD, PhD, FAMEE, is an Associate Professor and Research Programme Leader, Research in Education at the Faculty of Medicine, Vrije Universiteit Amsterdam. ORCID: 0002-9382-0379

Harish Thampy, MBChB, MRCGP, MSc, PFHEA, is Professor of Medical Education in the Faculty of Biology, Medicine and Health at the University of Manchester, UK. ORCID: 00000002-7850-4378

Keith W. Wilson, BA, MD, PhD, CCFP, FCFP, is Associate Professor of Family Medicine and Chair of Assessment at Dalhousie University, Canada. ORCID: 0000-0002-7027-5398 


\begin{abstract}
Scholarship in Health Professions Education is not just original research, it also includes study of educational processes, and application of new knowledge to practice. The pathways to successful scholarship are not always clear to novice educators. In this article, we describe strategies to establish a Community of Scholars (CoS), where more experienced and senior members guide junior members in scholarship to advance the field. Drawing on Lave and Wenger's concepts of Communities of Practice (CoP), we describe twelve practical tips, which include generation of a shared vision, formation of a global community of scholars, engagement in scholarly initiatives, and development of a professional identity, categorised under three major steps: establish, grow, and sustain the community. The tips embrace inclusivity for diverse cultural contexts which further provide opportunities for Health Professions Educators, interested in forming communities of practice, to work on scholarly outputs and add value to the professional arena.
\end{abstract}




\section{Introduction}

Scholarship in Health Professions Education (HPE) is increasingly recognised as a distinct area of expertise. Boyer recommended that scholarship should include scholarship of discovery (research), the accepted form of scholarship in academia; scholarship of integration (synthesis and application of information across disciplines); scholarship of application (applying theory or research findings to practice); and scholarship of teaching (systematic study of teaching and learning processes) (Boyer 1990). All approaches to scholarship require that one's work is disseminated, shared with peers, and available for peer-review. However, the avenues to successful scholarship are not always clear or accessible to individual educators. Being part of a community with access to mentorship can enhance the professional development of Health Professions Educators.

The Communities of Practice (CoP) concept was developed by cognitive anthropologist Jean Lave and educational theorist Etienne Wenger (Lave and Wenger 1991). While CoPs can evolve spontaneously due to shared interests in a specific domain, purposeful connections can contribute to identity formation, knowledge-sharing, mentoring relationships, and professional development for all involved (Steinert 2010). A Community of Scholars (CoS) is as a group of professionals, with a passion for successful scholarship and co-creation of knowledge, who collaborate in knowledge co-creation and dissemination (Wenger et al. 2002). Virtual CoPs primarily communicate remotely, unconstrained by geographical location, have access to a variety of experts across the world, and ideally comprise members from several regions of the 
world (Yarris et al. 2019). However, global CoPs should not only aim to share knowledge and skills, but also foster exploration, discussion, and incorporation of a variety of contexts and cultures, thus accelerating professional development of members.

The authors of this article have formed a virtual global CoS, the nucleus of which was created during a 'speed mentoring' workshop offered at the 2019 conference of the Association for Medical Education in Europe (AMEE) (Ramani et al. 2020). By mutual agreement, the CoS was maintained via email and video conferencing and the group published papers, presented workshops, and forged new working relationships. In this 12 Tips article, we describe strategies to form, grow, and sustain a virtual global CoS with a focus on scholarly outputs; educators interested in joining or forming scholarly communities can adapt these to their own context. The tips, mapped to three categories, are a synthesis of relevant literature and authors' experiences (Figure 1):

1. Establish the community- The community is formed guided by a shared purpose.

2. Grow the community- The community grows and completes projects.

3. Sustain the community- Group identity and commitment to the community are fostered.

\section{ESTABLISH A COMMUNITY- THE VISION}

\section{Tip 1- Identify a shared need or purpose}

CoPs can form spontaneously or deliberately around a shared vision (Wenger et al. 2002). A vision is the fundamental purpose for the group and can emerge from a sense of urgency (Kotter 1995) such as supporting educators in challenging situations (such as the Covid19 pandemic), or a desire to collaborate in scholarship. The vision and underlying values should to all potential members of the group and embrace a spectrum of global contextual and cultural 
perspectives. The leaders should clearly envision the purpose, achievable outcomes, optimal composition, process for recruiting members, and indicators of success.

The vision for our CoS, centred around mentoring educators in their professional growth as scholars and leaders, was driven by the conviction that a global narrative in HPE needs a network of scholars at a variety of career stages, from multiple regions of the world, with awareness of contextual and cultural variations, and a desire to develop, share and implement global solutions.

Figure 1: 3-stages in developing a Community of Scholars

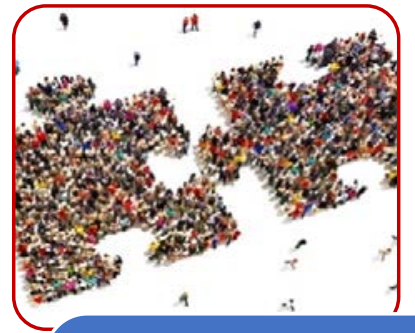

ESTABLISH THE

COMMUNITY - THE

VISION

-Identify a shared need or

purpose

- Develop and disseminate the

shared purpose, vision, and

work

- Start to build a community

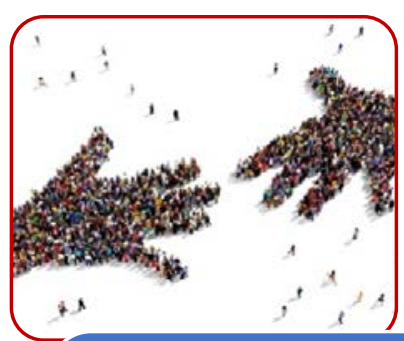

GROW THE

COMMUNITY-

ACTUALISATION

-Purposefully cultivate the CoP

- Rotate leadership,

management, \& follower roles

- Establish specific goals, tasks,

and projects

-Welcome and embrace diverse

socio-cultural contexts

- Promote and attend to

psychological safety

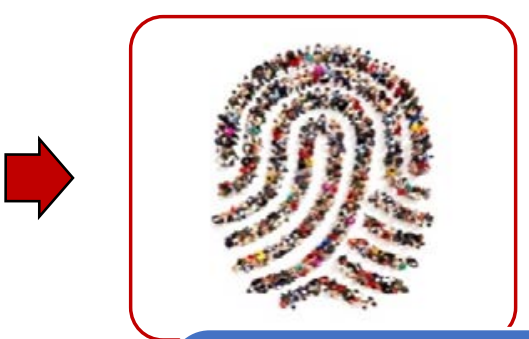

SUSTAIN THE

COMMUNITY - THE

IDENTITY

-Make space for social

interactions- virtual or in-

person

-Celebrate wins- small and large

- Reflect on what worked, what

did not

- Plan for longer term

sustainability 


\section{Tip 2- Develop and disseminate the shared purpose, vision, and work}

Embracing theoretical principles and worldviews can help underline the shared purpose and ground rules for a group. Social learning theory (learning as a process that occurs in a social context) is applicable to communications and relationships among members of a global CoS seeking to co-create and disseminate new knowledge (Bandura 1977; Burford 2012). Transformative learning (learning that transforms frames of reference to make individuals more reflective, open, inclusive and willing to change) can also be applied to motivate participants to be agents of change (Mezirow 1997; Halman et al. 2017).

The identity of individual members and the community can develop through co-creation of knowledge, projects embedded in shared values, and a vision that brings global learning cultures together. Ways of working and modes of communication should be agreed early on, such as frequency of meetings and how each member's contributions would be welcomed. Such approaches are critical to create a safe and collegial environment for members from different cultural backgrounds at different career stages. Our CoS communicated at least monthly through email and video conferencing, used online polls to schedule meetings, and established ground rules for meetings and scholarly projects. The group, self-titled 'Mentors without Borders,' decided that a small core was needed to efficiently initiate and complete projects, and plan mentoring initiatives. Yet, the CoS would continue to welcome new core members as well as individuals who wished to participate in limited ways.

\section{Tip 3- Start to build a community}

The first step in creating any enterprise is "getting the right people on the bus" (Collins 2001). In building a global CoS, networking is vital to reach out far and wide to identify potential members who share the vision (see Tip 3), represent different learning and societal 
cultures, offer a multitude of perspectives, and facilitate the sharing of a global vision. Cultural intelligence is critical when forming global communities, therefore groups should purposefully target diversity among its members (e.g., culture, gender, geographic location) with a range of knowledge and skills (e.g., content expertise, relationship building, strategic thinking) (Rath and Conchie 2008). Since such communities are often voluntary, time and effort must be invested in planting the seeds, nourishing the soil, and cultivating relationships so that they bear fruit. Different time zones pose challenges to synchronous discussions among a global community; patience and embracing varying contexts, cultures and perspectives are essential virtues.

Virtual networks, including social media and personal networks, minimise barriers of time, space, hierarchy, and travel limitations. Online platforms can also be used for mentoring and to support and celebrate successes of group members.

\section{GROW THE COMMUNITY- ACTUALISATION}

\section{Tip 4- Purposefully cultivate the community}

Professionals join a community to gain new knowledge or skills, network and obtain support from others, however, if the gap between their competence and experience is too narrow (nothing new to learn) or too wide (no capability to learn), it is unlikely that they would join the CoP. Through ‘legitimate peripheral participation’ individuals can join a group, then move from the periphery towards the centre to develop an identity as part of the community (Wenger 2010). According to Wenger, CoPs are characterised by the domain shared by the members of the community i.e. their shared purpose (in our $\operatorname{CoS}$ this is educational scholarship), the community i.e. relations and interactions between members, and the practice: ways of working, understanding, and sharing of resources. 
To purposefully cultivate a global CoP, members must constantly redefine and reinforce the shared purpose, ensure open and trustful communication, and develop shared understanding of concepts and values. CoPs should also focus on change in practice appropriate to the local context, not solely on knowledge and skills (Ranmuthugala et al. 2011). Key goals of our CoS were inclusion of educators from different international regions and cultures, co-creation of scholarly resources to advance the field, and mentorship of each other to enhance professional growth.

\section{Tip 5- Facilitate a variety of leadership, management, and follower roles}

A flexible approach can support group members in taking on various roles, based on their expertise, skills, availability, and needs. Consensus on clear outcomes for various workstreams is essential. Purposeful mentoring can allow individuals can learn from each other, develop their expertise, and move from the periphery to the centre of the CoP. Taking a transformational leadership approach, attention to individual needs and maintenance of psychological safety, will help motivate individuals to be more creative and reach their potential (Bass and Riggio 2006) Development of any community requires working within a dynamic 'leadership triad' (McKimm and O'Sullivan 2016). This involves a purposeful combination of collaborative, collective and distributed leadership (McKimm and McLean 2020), management (making things happen, project and time management) and active followership (the ability to support a leader, achieve goals and ensure the leader’s success) (McKimm and Vogan 2020). Leadership, management and followership roles should be rotated for different initiatives. A global CoS involves operating under complexity; working across (all types of) borders; taking an inclusive leadership approach (ensuring representation of differences); welcoming diverse views, challenging biases and assumptions, building community and commonality, and celebrating and learning from 
differences. The leadership of global CoPs requires 'boundary spanning': seizing and welcoming opportunities to work across organisations, cultures, countries, and viewpoints.

\section{Tip 6 - Establish specific goals, tasks, and projects}

To achieve the group’s vision, tasks and activities that require joint endeavours and shared resources should be identified. Goal-setting by individuals or a small group may lead to conflicts, therefore they should be jointly negotiated such that activities are a collaborative enterprise with a clear focus and deliverable outcomes (Locke and Latham 2006). Specific and challenging goals can generate higher task performance among the group members than easy to accomplish or vague goals (Kleingeld et al. 2011). A clear 'roadmap’ should outline key milestones to be achieved, timelines and checkpoints for progress updates. Numerous goals and multiple concurrent workstreams can be confusing and distracting: instead select two or three priorities that are SMART i.e. specific, measurable, assignable/achievable, realistic and time-bound (Doran 1981).

In our CoS, goals focussed on writing for publication and organisation of in-person and online workshops. We were mindful that our members were diverse culturally, geographically and in scholarly experience and expertise. Consequently, we matched activities to individuals’ preferences and skillset, and incorporated a 'buddy' system whereby more experienced members supported newcomers/novices to engage and gradually take on increasing responsibilities.

\section{Tip 7- Welcome and embrace diverse socio-cultural contexts}

Culture (societal or organisational) comprises norms, shared values, attitudes, and practices, which guide behaviour and interactions of a group of individuals. Schein describes three distinct levels of culture: (1) Artefacts: visible behaviours of the group, (2) Espoused values: the stated guiding values, and (3) Assumptions: deeply embedded, usually unconscious 
behaviours (Schein 2004). Educational culture is influenced by societal and organisational culture, therefore educational practices, expectations, and behaviours vary widely in different regions of the world, even at different institutions in the same region.

In HPE, Western research and expert recommendations are often applied in non-Western countries where societal, organisational and learning cultures are markedly different (Bleakley et al. 2008). Such application may not meet local needs, reduce opportunities to share multiple perspectives and foster mutually beneficial interactions. As we formed our global CoS, we consciously reached out to educational scholars and leaders from different regions of the world so that all members of the CoS could respect diverse socio-cultural contexts, continually learn from their counterparts across the world and actively engage in cross-cultural scholarly collaborations. Such inclusivity allowed us to tap into the wisdom of our diverse group, continue to learn from one other and celebrate the richness of our societal and learning cultures (Watling 2015).

\section{Tip 8- Promote and continuously attend to psychological safety}

Psychological safety, defined as "showing one's self without fear of negative consequences to self-image, status or career" (Edmondson 2019), takes time to develop,and perceived threats will slow down the process. If people feel unsafe, trusting relationships cannot be built and individuals will avoid taking risks needed to complete interdependent work and grow. Creating psychological safety in large and/or global CoPs can be very complex. It is imperative that the CoS leadership considers language difficulties, cultural differences, interprofessional hierarchies, time zones, resource limitations and governmental restrictions, and ensures that the vision is reinforced by a variety of contextual and cultural perspectives, 
challenges and practices. Whether the community meets in person or virtually, input from quieter members must be solicited to enhance safety and mutual trust.

Many strategies can enhance psychological safety (Clark 2020). Leaders should start out with a warm welcome, establish clear ground rules, emphasise that all members can make unique contributions and actively welcome ideas from all. In fact, a meaningful global vision must include input from educators from many parts of the world; in this situation consensus should not default to a unidimensional Western lens. Leaders should role-model behaviours, encourage contributions from all members explicitly as well as implicitly, thus acknowledging participants' value and roles. Conflicts need to be addressed expeditiously. Global CoS which develop in a virtual context will grow gradually and in phases; it will take time for members to develop a sense of belonging to the community and take pride in its achievements. Effective leaders must encourage participation by every single group member as well as foster a sense of belonging and pride.

\section{SUSTAIN THE COMMUNITY- THE IDENTITY}

\section{Tip 9- Make space for social interactions- virtual or in-person}

Social interactions are critical to foster a sense of accomplishment, enable the creation of social intellectual capital, and develop social identity (Adler and Kwon 2002). Relationships among CoS members are meaningful when they are supportive and based on common values (Adler and Kwon 2002). Successful social networks balance both strong and weak ties (Levin 
and Cross 2004). While the inner circle of a network features strong ties that translate mutual interests and goals, weak ties bring diverse experiences, creative insights and broaden the overall reach of the community. For an online $\mathrm{CoS}$, it is especially vital to have a "bond, a measure of commitment, a set of shared values, a culture, a history, and a shared identity” (Driskell and Lyon 2002).

In developing a motivated, active, and fulfilled international CoS, providing opportunities for members to get to know each other is essential. This might be achieved by icebreakers at the beginning of encounters to share personal interests and pursuits other than the group's work (our meetings start with a fun fact from each member, or what is happening in their part of the world), demonstration of interest in each other's wellbeing, acknowledgment of diverse ideas, celebration of others’ achievements, and allocation of time for informal interactions.

\section{Tip 10 - Celebrate wins - small and large}

Any CoP is held together by "passion, commitment and identification with the group's expertise" (Wenger. and Snyder 2000). The group should actively seek out opportunities to facilitate a meaningful “quick visible win” (Kotter 1995) early in its formation to motivate team members and give them a sense of accomplishment as a team. Identifying a common task with meaning for all members will allow the group to generate that early progress, break down barriers and encourage collaboration. Team members can also enhance intrinsic motivators by recognising each other's contributions (Amabile and Kramer 2011).

In developing a quick win, the CoS needs to define how success can reflect the passion and commitment of its members. It might be a joint publication or sharing of expertise and resources. Equally important is preparing for and defining potential failures (such as a rejected publication, member departure) and viewing them as opportunities for learning; more 
experienced members can model how to deal with such failures and provide a potent intrinsic motivator for creativity and perseverance.

\section{Tip 11 - Reflect (in, on and for action) and evaluate what worked, what did not}

To sustain a CoP, reflective practice (in, on and for action) needs to be encouraged and embedded into the ground rules (Johnston and Fells 2017). This is particularly relevant to a global CoS with its diversity of cultures, ideas, and experiences. Facilitating reflection-in-action (whilst activities are ongoing) enables members to share ideas and co-create something that is more than any individual could do alone. This requires trust and psychological safety. Reflection-on-action is vital for learning to occur following the activities of the CoS.

Taking a quality improvement (QI) and enhancement approach that includes formal processes of reflection and evaluation on what has been done well and what should be improved, inviting the rich perspectives of the members, can help the CoS become stronger and more effective. Furthermore, reflection-for-action (as pre-action reflection) can be conducted based on the cumulative lessons learned in order to anticipate what can be improved in future activities (Ong 2011). Reflection in, on and for action should be integrated when formally or informally evaluating achievement of short- and long-term objectives of a CoS. In our group, availability of members from different parts of the world enabled us to have rich and reflective conversations about contextual and cultural similarities and differences; as a result new cross-cultural educational and scholarly collaborations have been forged.

\section{Tip 12- Plan for longer term sustainability}

A well-functioning global CoS will attain its own identity, work ethic, and generate outputs beneficial to group members and educators across the world. Even in the most productive groups, there will be departures and new entrants over time. Early planning with 
attention to minimising impact on personal and professional life, regular communications via email and video conferencing, gauging available support and resources, group dynamics, ethical ground rules and technological accessibility (or alternative modes of communication) will ensure long-term sustainability of the CoS (Swift 2014; Toriida et al. 2015; Poon and Lam 2017). Since contribution to the CoS requires additional commitment and resources from scholars, members' ability to apply lessons learned to their own work settings may motivate organisations to support the community. Literature emphasises the importance of collegial dynamics, internal mentoring opportunities and a problem-solving approach to conflicts in sustaining CoPs (Toriida et al. 2015). Issues related to conflicts of interests, confidentiality and data privacy should be monitored. A virtual CoS can create an inclusive venue for sharing perspectives and solutions with agility and adaptability, unrestricted by factors such as politics, travel or rigid organisational structures (Duryan and Smyth 2019). Continued relevance to the profession and achievement of shared goals will help ensure longer-term sustainability.

Effective CoPs need a strong and unified vision, a safe environment, members from diverse contexts and cultures, and a nurturing mindset. Leaders should pay attention to sustaining the community long-term and not just on task completion. To promote this, the importance of followership should be acknowledged, leadership and management roles should be rotated for different tasks, members should be given choices to engage based on the task and their work and personal commitments. However, the larger a community gets, the more inefficient its working methods and output can become. Therefore, group leaders should decide on the optimal number of members in which the cultural diversity is maintained while driving the community onward and upward. 


\section{Conclusion}

The tips presented in this article can be used by scholars and leaders in Health Professions Education across the world intending to start Communities of Scholars (CoS) at their own institutions or beyond. These groups are likely to gain importance, as travel for international conferences may remain restricted in the post-pandemic world. Continuous collaboration and mentoring can foster a unique identity for members of a CoS as well as stimulate successful scholarship. Most of all, such a community is supportive and motivating, and brings joy and pride to its members.

It is appropriate for a global Community of Practice to adapt a quote by Mother Teresa, "We alone cannot change the world, but we can cast a stone across the waters to create many ripples.”

\section{References}

1. Adler PS, Kwon S. 2002. Social capital: Prospects for a new concept. Acad Management Rev. 27(1):17-40.

2. Amabile T, Kramer SJ. 2011. The Power of Small Wins. . Harvard Bus Rev (May):3-12.

3. Bandura A. 1977. Social learning theory. Englewood Cliffs, N.J.: Prentice Hall. 
4. Bass BM, Riggio RE. 2006. Transformational leadership. 2nd ed. Mahwah, N.J.: L. Erlbaum Associates.

5. Bleakley A, Brice J, Bligh J. 2008. Thinking the post-colonial in medical education. Med Educ. 42(3):266-270.

6. Boyer EL. 1990. Scholarship reconsidered : priorities of the professoriate. Princeton, N.J.: Carnegie Foundation for the Advancement of Teaching.

7. Burford B. 2012. Group processes in medical education: learning from social identity theory. Med Educ. 46(2):143-152.

8. Clark TR. 2020. The 4 stages of psychological safety : defining the path to inclusion and innovation. First edition. ed. Oakland, CA: Berrett-Koehler Publishers, Inc.

9. Collins JC. 2001. Good to great : why some companies make the leap--and others don't. 1st ed. New York, NY: HarperBusiness.

10. Doran GT. 1981. There's a S.M.A.R.T. Way to Write Management's Goals and Objectives. Management Review. 70(11):35-36.

11. Driskell RB, Lyon L. 2002. Are Virtual Communities True Communities? Examining the Environments and Elements of Community. City and Community. 1(4):373-390.

12. Duryan M, Smyth H. 2019. Cultivating sustainable communities of practice within hierarchical bureaucracies: The crucial role of an executive sponsorship. International Journal of Managing Projects in Business. 12:400-422.

13. Edmondson AC. 2019. The fearless organization : creating psychological safety in the workplace for learning, innovation, and growth. Hoboken, New Jersey: John Wiley \& Sons, Inc. 
14. Halman M, Baker L, Ng S. 2017. Using critical consciousness to inform health professions education : A literature review. Perspect Med Educ. 6(1):12-20.

15. Johnston S, Fells R. 2017. Reflection-in-action as a collective process: findings from a study in teaching students of negotiation. Reflective Practice. 18(1):67-80.

16. Kleingeld A, van Mierlo H, Arends L. 2011. The effect of goal setting on group performance: A meta-analysis. Journal of Applied Psychology. 96:1289-1304.

17. Kotter JP. 1995. Leading Change: Why Transformation Efforts Fail. Harvard Bus Rev.(May-June):59-67.

18. Lave J, Wenger E. 1991. Situated learning : legitimate peripheral participation. Cambridge England ; New York: Cambridge University Press. (Series Title: Learning in doing.

19. Levin DZ, Cross R. 2004. The Strength of Weak Ties You Can Trust: The Mediating Role of Trust in Effective Knowledge Transfer. Management Science. 50(11):1477-1490.

20. Locke EA, Latham GP. 2006. New Directions in Goal-Setting Theory. Current Directions in Psychological Science. 15(5):265-268.

21. McKimm J, McLean M. 2020. Rethinking health professions' education leadership: Developing 'eco-ethical' leaders for a more sustainable world and future. Med Teach. Epub date: 2020/04/15(DOI: 10.1080/0142159X.2020.1748877):1-6.

22. McKimm J, O'Sullivan H. 2016. When I say ... leadership. Med Educ. 50(9):896-897. 23. McKimm J, Vogan CL. 2020. Followership: much more than simply following the leader. BMJ Leader. Published Online First: 06 February(DOI: 10.1136/leader-2019000162). 
24. Mezirow J. 1997. Transformative learning: Theory to practice. New directions for adult and continuing education. 1997(74):5-12.

25. Ong K. 2011. Reflection for action in the medical field. Reflective Practice. 12(1): 145149.

26. Poon MK, Lam TP. 2017. Factors Affecting the Development and Sustainability of Communities of Practice Among Primary Care Physicians in Hong Kong. J Contin Educ Health Prof. 37(2):70-75.

27. Ramani S, Thampy H, McKimm J, Rogers GD, Hays R, Kusurkar RA, Schumacher DJ, Kachur EK, Fornari A, Chisolm MS et al. 2020. Twelve tips for organising speed mentoring events for healthcare professionals at small or large-scale venues. Med Teach. Epub date: 2020/03/27(DOI: 10.1080/0142159X.2020.1737323):1-8.

28. Ranmuthugala G, Plumb JJ, Cunningham FC, Georgiou A, Westbrook JI, Braithwaite J. 2011. How and why are communities of practice established in the healthcare sector? A systematic review of the literature. BMC Health Serv Res. 11(273):DOI:10.1186/14726963-1111-1273.

29. Rath T, Conchie B. 2008. Strengths based leadership : great leaders, teams, and why people follow. New York: Gallup Press.

30. Schein E, H. 2004. Organizational culture and leadership. 3rd ed. San Francisco: JosseyBass. (The Jossey-Bass business \& management series).

31. Steinert Y. 2010. Faculty development: from workshops to communities of practice. Med Teach. 32(5):425-428.

32. Swift L. 2014. Online communities of practice and their role in educational development: a systematic appraisal. Community Pract. 87(4):28-31. 
33. Toriida M, Ronaldson S, Fournier B, Blanke S. 2015. Sustaining a community of scholars at a transnational university: A self-study. European Scientific Journal. 1:172-190.

34. Watling C. 2015. When I say ... learning culture. Med Educ. 49(6):556-557.

35. Wenger E. 2010. Complex tools for CoPs as social learning systems: Boundaries, Trajectories, Identity and Participation. Ed: 2010. pgs. . In: Blackmore C, editor. Social Learning Systems and Communities of Practice. Open University, United Kingdom.: Springer p. 125-143.

36. Wenger E, McDermott RA, Snyder W. 2002. Cultivating communities of practice : a guide to managing knowledge. Boston, Mass.: Harvard Business School Press.

37. Wenger., Snyder WM. 2000. Communities of Practice: The Organizational Frontier. Harvard Bus Rev.(Jan-Feb):139-145.

38. Yarris LM, Chan TM, Gottlieb M, Juve AM. 2019. Finding Your People in the Digital Age: Virtual Communities of Practice to Promote Education Scholarship. J Grad Med Educ. 11(1):1-5. 